\title{
Gerenciamento de Resultados em Bancos Mediante a Divulgação do Lucro Ajustado por Itens Extraordinários
}

\author{
Monize Ramos do Nascimento \\ https://orcid.org/0000-0001-8832-3004 \\ Raíssa Aglé Moura de Sousa \\ https://orcid.org/0000-0001-9302-5087 \\ José Alves Dantas \\ https://orcid.org/0000-0002-0577-7340 \\ João Tupinambá Gomes Neto \\ https://orcid.org/0000-0001-5080-3336 \\ Wellington Alves de Oliveira \\ https://orcid.org/0000-0003-4380-8926
}

\section{Resumo}

Objetivo: Investigar evidências de gerenciamento de resultados por meio da divulgação do lucro ajustado (lucro líquido menos itens extraordinários) pelos bancos brasileiros, considerando que os gestores podem utilizar a discricionariedade na divulgação gerencial dos resultados para melhorar remuneração ou influenciar investidores.

Método: Foram realizadas estimações de modelo de regressão linear (efeitos fixos), com dados trimestrais, de 2016 a 2020, de 21 bancos brasileiros listados na B3.

Resultados: Os testes empíricos revelaram associação positiva entre os itens extraordinários e o lucro líquido, sem os efeitos dos ajustes dos itens extraordinários, confirmando a hipótese de que tais entidades usam a divulgação do lucro ajustado como mecanismo de gerenciamento das expectativas dos investidores, suavizando a parcela recorrente do lucro.

Contribuições: Sob a ótica de mercado, a pesquisa contribui para alertar os investidores e reguladores a ponderarem os ajustes efetuados na evidenciação dos resultados gerenciais (Non-Gaap). Em relação aos padrões contábeis internacionais, colabora com as discussões do Exposure Draft ED/2019/7 - General Presentation and Disclosures, propostas pelo Iasb, ao evidenciar a prática dos bancos brasileiros de capital aberto na divulgação dos itens de natureza não recorrentes, o que contribui para reduzir a assimetria informacional na relação principal-agente.

Palavras-chave: Gerenciamento de resultados; Bancos. Itens extraordinários; Lucros recorrentes; Medidas non-gaap. 


\section{Introdução}

Este estudo investiga evidências de gerenciamento de resultados por meio da divulgação do lucro ajustado (lucro líquido menos itens extraordinários) pelos bancos brasileiros. A premissa que dá suporte a essa expectativa é que os gestores podem utilizar a discricionariedade implícita na divulgação gerencial dos resultados para manipulá-los por algum estímulo, como alcançar uma melhor remuneração ou mesmo para aumento do valor de mercado da entidade (Cain, Kolev, \& McVay, 2020). Isso pode se dar a partir da classificação, como itens extraordinários, de transações que integram o lucro líquido e que representem um impacto negativo sobre o desempenho da entidade, indicando uma possível falta de neutralidade na abordagem (IASB, 2019). A pesquisa se insere, assim, na literatura de uso de medidas non-gaap - métricas e informações adicionais, não requeridas nas normas contábeis - no mercado de capitais, em que as entidades divulgadoras procuram influenciar as expectativas dos investidores.

A prática do gerenciamento de resultados tem sido objeto de grande interesse da literatura contábil, desde os últimos anos do século 20, conforme sintetizado nas surveys realizadas por Schipper (1989), Healy e Wahlen (1999) e Dechow e Skinner (2000), com especial impacto do desenvolvimento de modelos para mensuração dessa prática - como em Jones (1991) e Dechow, Sloan e Sweeny (1995), por exemplo. No Brasil, teve como marco o estudo de Martinez (2001) e adquiriu relevância a partir de então, conforme documentado na survey apresentada por Martinez (2013).

Esse tipo de pesquisa tem alcançado de forma relevante as entidades do sistema financeiro, não obstante o ambiente regulado em que os bancos estão inseridos. Isso porque essa regulação não é suficiente para suprimir os chamados conflitos de agência e eventuais oportunidades na legislação ou na estrutura normativa que podem ser utilizados para o comportamento oportunista e discricionário, com o propósito de gerenciamento de resultados, envolvendo tanto a suavização de lucros ao longo dos períodos quanto a intenção de apresentar melhores resultados e indicadores econômico-financeiros. Nesse contexto, a literatura sobre o gerenciamento de resultados em instituições financeiras tem se concentrado no uso de provisões para perdas associadas ao risco de crédito (Alali \& Jaggi, 2010; Curcio \& Hasan, 2015; Dantas, Medeiros, \& Lustosa, 2013; Kanagaretnam, Krishnan, \& Lobo, 2010; Macedo \& Kelly, 2016; Silva, Niyama, Rodrigues \& Lourenço, 2018; Silva \& Robles Júnior, 2018; Soedarmono, Pramono \& Tarazi, 2017) e da marcação a valor justo de instrumentos financeiros, incluindo derivativos (Beatty \& Harris, 1999; Beatty, Ke, \& Petroni, 2002; Dantas, Galdi, Capelletto, \& Medeiros, 2013; Dantas, Medeiros, Galdi, \& Costa, 2013; Gabriel \& Corrar, 2010; Shrieves \& Dahl, 2003; Zhuang, 2016).

Embora a literatura sobre gerenciamento de resultados seja ampla, a avaliação dessa prática a partir da utilização de medidas non-gaap, em especial o uso da divulgação de componentes do lucro como itens extraordinários, sinalizando não ser esperado que esses se repitam nos períodos seguintes, ainda são incipientes - McVay (2006), Barua, Lin e Sbraglia (2010), Fan, Baura, Cready e Thomas (2010), Lopes, Pinheiro e Dias Filho (2014) e Li, Su, Dong e Zhu (2018) são exemplos de pesquisas a respeito. A premissa subjacente a essa relação estudada é que o conteúdo das informações financeiras divulgadas, incluindo as medidas non-gaap, exerce influência nos processos decisórios dos agentes econômicos e pode implicar em transferência de riqueza. Dessa forma, as entidades evidenciariam tais informações em quantidade e qualidade necessárias, na medida em que os incentivos econômicos fossem superiores aos da não divulgação (Suzart, 2015). 
A possível falta de neutralidade na abordagem de divulgação desses itens tem merecido atenção por parte do International Accounting Standards Board [(Iasb), que tem realizado discussões a respeito do tema, demonstrando preocupação em relação à forma como as entidades apresentam as informações sobre esses itens incomuns, já que variam significativamente de acordo com a entidade e muitas vezes não ficam claros os critérios de classificação. Por essa razão, o Iasb incorporou o Exposure Draft ED/2019/7 - General Presentation and Disclosures, em que é discutida a revisão do modelo de apresentação da demonstração de resultados, a previsão de divulgação dos resultados não usuais ou não recorrentes. O propósito é que essa divulgação, que atualmente integra o rol de medidas non-gaap, passaria a ser disciplinada nas normas contábeis, incluindo critérios que assegurem um padrão de consistência e de uniformidade que possibilite a comparabilidade ao longo do tempo e entre entidades.

Este estudo se propõe a preencher uma lacuna na literatura sobre gerenciamento de resultados em instituições financeiras, ao focar em uma forma alternativa de identificar essa prática oportunista, por meio do uso da classificação de componentes do resultado como itens extraordinários. Mesmo com foco nas entidades bancárias brasileiras, com suas características específicas, a pesquisa também contribui para criar expectativas sobre o uso dos itens extraordinários em outros segmentos econômicos, na medida que a reação aos incentivos econômicos dessa prática nos demais segmentos pode ter algum grau de similaridade. O que se espera identificar é se as demonstrações financeiras dos bancos brasileiros apresentam indícios de viés na evidenciação dos itens extraordinários, o que pode comprometer a sua fidedignidade e neutralidade, além de induzir os diversos usuários da informação (com destaque para os acionistas, os reguladores e os credores) a erro no processo decisório. A classificação de determinados itens do resultado como de caráter extraordinário sinaliza que não devem se repetir nos períodos seguintes, influenciando a percepção dos usuários sobre o que seria o resultado recorrente.

Importante ressaltar que pode ser difícil para os investidores detectar esse tipo de gerenciamento (manipulação) de resultados, tendo em vista que não altera o lucro líquido - ao contrário do gerenciamento com o uso de perdas associadas ao risco de crédito ou ao reconhecimento do valor justo de instrumentos financeiros, por exemplo - e pode ser uma forma menos onerosa de gerenciamento de resultados (Barua, Lin, \& Sbraglia, 2010). Se constitui, portanto, em abordagem menos óbvia sobre o gerenciamento de resultados em bancos, em que os gestores influenciariam as expectativas de resultados futuros, sem alterar a medida do resultado presente.

Para a realização dos testes empíricos foram analisados dados trimestrais, de 2016 a 2020, dos 21 bancos brasileiros de capital aberto com ações negociadas na Brasil, Bolsa Balcão (B3)]. Os resultados dos testes empíricos revelaram haver associação positiva entre os itens extraordinários e o lucro líquido, antes de se considerar a reclassificação dos itens extraordinários.

Essas evidências são compatíveis com as premissas da suavização do lucro líquido ajustado proxy para o que seria o resultado recorrente. Isso sugere que os gestores bancários procuram influenciar as expectativas dos usuários em relação aos resultados futuros, utilizando a classificação como "itens extraordinários" para comunicar maior estabilidade e previsibilidade da parcela "ordinária" do lucro, influenciando as expectativas dos usuários sobre os resultados futuros, em consonância com a literatura existente. Ademais, os resultados do estudo oferecem evidências que reforçam a preocupação do Iasb com a edição do ED-2019/7, que é a necessidade de disciplinar a divulgação dos eventos não usuais ou não recorrentes, de forma a instituir critérios mínimos que assegurem a neutralidade da divulgação. 


\section{Revisão de Literatura}

\subsection{Gerenciamento de Resultados em Instituições Financeiras}

Tendo em vista que o objetivo das demonstrações financeiras é fornecer informações úteis para facilitar a alocação eficiente de recursos e as decisões das partes interessadas, os gerentes devem ter discricionariedade e julgamento para transmitir informações sobre o desempenho das empresas quando houver assimetria (Cohen \& Zarowin, 2007). Porém, essa discricionariedade pode ser utilizada para maximizar o valor oportunisticamente, ou seja, os gestores podem utilizar-se dos incentivos para transmitir informação em benefício próprio, escolhendo métodos e estimativas contábeis que não refletem adequadamente as condições econômicas subjacentes, abrindo espaço para o gerenciamento de resultados (Araújo, Lustosa, \& Paulo, 2018; Watts \& Zimmerman, 1986).

Schipper (1989) define gerenciamento de resultados como uma intervenção proposital no processo de elaboração das demonstrações financeiras externas, com intenção de obter algum benefício particular. Alternativamente, para Healy e Whalen (1999) o gerenciamento de resultados ocorre quando os gestores usam julgamentos orientados nos relatórios e na estruturação de transações para alterar as demonstrações financeiras. Por fim, Martinez (2013) explica que o gerenciamento ocorre, seja para alterar a percepção dos stakeholders sobre as atividades da entidade, seja para alcançar o resultado esperado em acordos vinculados aos números contábeis divulgados.

As ações oportunistas dos gestores em detrimento dos acionistas/investidores podem ser decorrentes dos conflitos de interesses existentes entre os agentes (gestores) e os principais (acionistas/investidores), subsidiados pela Teoria da Agência, cujo foco é na determinação do contrato mais eficiente para guiar o relacionamento agente-principal (Eisenhardt, 1988). Jensen e Meckling (1976) previam que ao firmar um contrato baseado em resultados, seria mais provável que o agente tivesse um comportamento alinhado aos interesses do principal, já que as recompensas tanto para o agente quanto para o principal são dependentes das mesmas ações. Com isso, os contratos baseados em resultados seriam mais efetivos para inibir o oportunismo gerencial.

Dittmann e Maug (2007) afirmam que, visando reduzir os impactos provenientes dos conflitos de interesses da relação agente-principal, os acionistas passaram a fornecer pacotes de remuneração aos gestores, os quais normalmente estão atrelados aos resultados, de modo a alcançar, inclusive, o desempenho esperado. Contudo, considerando-se que os agentes têm preferências e que tendem a atingir os seus benefícios pessoais, ao contrário de colaborar efetivamente com a valorização das empresas (Jensen \& Meckling, 1976), os gestores podem se utilizar das informações contábeis para gerenciar os resultados e, por exemplo, alcançar a remuneração desejada, além de ter o desempenho almejado pelos principais como um produto do gerenciamento.

Nas instituições financeiras, o gerenciamento de resultados pode ocorrer de diversas formas, como, por exemplo, por meio da provisão para perdas associadas a risco de crédito (PECLD), de mensuração a valor justo de instrumentos financeiros e de seu reconhecimento como resultado do período ou como outros resultados abrangentes ou de manipulações diretamente no lucro. Esse tipo de entidade tem um incentivo para manipular os ganhos porque os lucros contábeis transmitem informações aos investidores e desempenham um papel relevante na avaliação do desempenho da entidade e na contratação baseada em contabilidade (Warfield, Wild, \& Wild, 1995).

Vários estudos empíricos buscaram evidências para o gerenciamento de resultados em entidades bancárias. Curcio e Hasan (2015), por exemplo, encontraram evidências que ele é um fator importante que afeta decisões de provisionamento para perdas de risco de crédito em bancos da União Europeia e outros países europeus não pertencentes à União Europeia. Dantas, Medeiros e Lustosa (2013) identificaram resultados que demonstram que a PECLD é utilizada para gerenciar os resultados. No mesmo sentido, mas tendo como foco a presença de capital estrangeiro, Macedo e Kelly (2016) demonstraram que existem indícios de que a formação de PECLD esteja sendo influenciada pelo nível do lucro. 
Mais tarde, Silva e Robles Júnior (2018) confirmaram a relevância da PECLD, principalmente no resultado das instituições financeiras, devido a esta provisão atuar como fonte redutora da carteira de crédito e impactar diretamente o resultado de tais entidades. Outra abordagem de gerenciamento em bancos foi realizada por Dantas, Medeiros, Galdi e Costa (2013), que buscaram identificar se existe discricionariedade em relação ao reconhecimento e mensuração de instrumentos financeiros derivativos para o gerenciamento de resultados, constatando que essa prática é utilizada pelos bancos para alisamento dos resultados e que ocorre com maior frequência nas instituições privadas, com menor dimensão de ativos e menor nível de capitalização.

Já Koch, Waggoner e Wall (2018) examinaram o impacto das orientações recentes das agências bancárias dos Estados Unidos da América (EUA) na compensação de incentivos nos esforços para que os bancos criem amortecedores de capital anticíclicos que possam absorver perdas durante períodos de fraqueza econômica. Os resultados sugerem que as orientações relacionadas à remuneração baseada em ganhos contábeis criam incentivos de gerenciamento de resultados consistentes com os amortecedores de capital anticíclicos. No entanto, as partes que incentivam o pagamento de remuneração na forma de instrumentos vinculados a ações podem estabelecer incentivos para que os gerentes seniores reduzam os amortecedores de capital durante períodos de ganhos mais altos.

Esses são alguns exemplos de estudos que abordaram o gerenciamento de resultados em instituições financeiras, com clara preponderância daqueles que exploram as provisões associadas a risco de crédito, o que se justifica em função desses representarem os principais accruals bancários (Kanagaretnam, Lim, \& Lobo, 2010), mas também envolvendo outros tipos de operações ou informações.

\subsection{Gerenciamento de Resultados através do Lucro Ajustado}

O gerenciamento de resultados envolvendo o lucro ajustado pode ocorrer pelo reconhecimento de itens extraordinários, com o intuito de influenciar o resultado a ser distribuído (Lopes, Pinheiro, \& Dias Filho, 2014). Depreende-se, de uma análise preliminar na divulgação das demonstrações financeiras, que os bancos brasileiros classificam como itens extraordinários receitas e despesas que transitam pelo resultado, mas que não são decorrentes da intermediação financeira e das rendas decorrentes da prestação de serviços. É comum que os bancos classifiquem como itens extraordinários, por exemplo, parte das demandas legais cíveis e fiscais, despesas com planos de demissão e aposentadoria, créditos tributários não recorrentes, lucro ou prejuízo na alienação de participações, dentre outros, conforme evidenciado nas divulgações ao mercado dos resultados trimestrais dessas entidades.

Essas primeiras impressões sugerem que transações ou eventos com impacto negativo sobre os resultados da entidade (despesas/perdas) são mais frequentemente classificadas como incomuns ou pouco frequentes do que as transações e eventos positivos (receitas/ganhos). Isso sugere uma possível falta de neutralidade na abordagem, o que justifica e reforça a preocupação do Iasb com a edição do ED-2019/7, em que propõe disciplinar a divulgação dos itens de resultado não usuais ou não recorrentes. Embora não sejam disciplinados atualmente em normas contábeis, os itens extraordinários são entendidos como todos aqueles que não decorrem da atividade intrínseca da entidade, não sendo, portanto, uma nova classificação em operacional e não operacional, pois possuem a característica de serem imprevisíveis. Diferentemente dos ganhos gerados pela operação contínua, esses tipos de itens são únicos e contingentes (Li, Su, Dong, \& Zhu, 2018).

Com a convergência contábil no Brasil aos padrões IFRS, a apresentação dos itens extraordinários na demonstração do resultado passou a ser vedada, conforme definido pela International Accounting Standards (IAS) 1 - Apresentação das Demonstrações Contábeis - em seu item 87: "A entidade não deve apresentar rubricas ou itens de receitas ou despesas como itens extraordinários, quer na demonstração do resultado abrangente, quer na demonstração do resultado do período, quer nas notas explicativas". A partir das demonstrações anuais de 2020, por força da Resolução BCB n. ${ }^{\circ}$, de 2020, foi instituída a obrigatoriedade da divulgação, nas notas explicativas, dos resultados recorrentes e não recorrentes de forma segregada. 
Esse movimento do Banco Central do Brasil (BCB), em antecipação à disciplina pretendida pelo Iasb, está em linha com a afirmação de Flores e Lopes (2019) de que a partir da publicação do IFRS 14 Regulatory Deferral Accounts as entidades de atividades reguladas puderam adotar os padrões internacionais para publicação das demonstrações financeiras, junto com as demonstrações com fins regulatórios. Assim, ganhou evidência a publicação dos itens extraordinários nas demonstrações de resultados.

Alguns estudos empíricos foram desenvolvidos a respeito da temática. McVay (2006), por exemplo, examinou a classificação dos itens extraordinários na divulgação financeira como uma ferramenta de gerenciamento de resultados. As evidências demonstraram que os gerentes oportunisticamente transferem as despesas essenciais para os itens extraordinários, e os investidores agem como se fossem surpreendidos no período seguinte, quando essas despesas voltam aos lucros essenciais no ano seguinte. Em uma metodologia semelhante a McVay (2006), Barua, Lin e Sbaraglia (2010) identificaram que gestores também classificavam despesas operacionais de modo oportuno como operações descontinuadas, com a finalidade de inflar os lucros básicos para atender às expectativas de analistas. Em continuação a esses trabalhos, Fan, Barua, Cready e Thomas (2010) encontraram mais evidências de mudança de classificação quando a capacidade dos gerentes de manipular accruals parece estar restrita em atender a uma série de benchmarks de ganhos. No geral, as evidências forneceram amplo apoio à conclusão de McVay (2006) de que os gerentes se envolvem de forma não neutra na mudança de classificação. O estudo também lançou um novo entendimento das condições sob as quais os gerentes têm maior probabilidade de empregar mudanças na classificação.

No reconhecimento dos itens extraordinários, segundo Andrade e Múrcia (2019), deve ser verificado se são não recorrentes e não estão relacionados com as atividades da companhia. Eles são lançados após o lucro líquido, aumentando ou diminuindo o lucro líquido final, impactando diretamente na constituição de reservas e distribuição de dividendos. A possibilidade de gerenciamento de resultados surge da discricionariedade do julgamento profissional na sua divulgação, em que o desempenho da empresa seria demonstrado ao mercado conforme interesse do agente em detrimento do principal.

Com base no exposto, foi formulada a seguinte hipótese de pesquisa, a ser testada empiricamente:

$H_{1}$ : Os bancos brasileiros de capital aberto utilizam a divulgação de itens extraordinários como mecanismo de gerenciamento de resultados, por meio do alisamento da medida de lucro ajustado proxy do resultado recorrente.

\section{Procedimentos Metodológicos}

\subsection{Dados}

A pesquisa foi delimitada ao segmento bancário, a fim de analisar o comportamento dos bancos brasileiros listados na Brasil Bolsa Balcão (B3). Tais entidades estão obrigadas a obedecer às decisões do Conselho Monetário Nacional (CMN), como órgão normativo, do BCB, como órgão supervisor, além da Comissão de Valores Mobiliários (CVM).

Conforme Lopes, Pinheiro e Dias Filho (2014), seria plausível aceitar que, em um setor bem regulado, o gerenciamento de resultados assume comportamento diferenciado, tendo em vista que haveria menos estímulos ao gerenciamento devido à maior quantidade e qualidade de informação requerida pelos reguladores. Segundo Pelucio-Grecco, Geron, Grecco e Lima (2014) o ambiente regulatório no Brasil é o fator restritivo mais eficaz no combate ao gerenciamento de resultados. Adicionalmente, a opção em se concentrar especificamente nos bancos de capital aberto se justifica tanto pela disponibilidade dos dados nas bases consultadas quanto pelo fato de tais entidades terem mais incentivos econômicos para buscarem influenciar as expectativas dos usuários, em especial os investidores, sobre a medida de lucro recorrente. 
O estudo contou com dados de 21 bancos brasileiros que em junho de 2021 tinham ações negociadas na B3 e que possuíam informações disponíveis na base de dados da Refinitiv Eikon e Economática. Dessa forma, foram coletadas informações trimestrais, entre os anos de 2016 a 2020, que totalizaram 420 observações (banco/trimestre), das quais 3 foram excluídas, devido à insuficiência de dados de pelo menos uma das variáveis para a composição do modelo econométrico utilizado na pesquisa. Assim, tal estudo resultou em um painel desbalanceado de 417 observações (banco/trimestre).

Os dados foram segregados em DOIs blocos: (a) bloco 1, contendo todas as 417 observações banco/ trimestre que reportaram saldos contábeis; e, (b) bloco 2, formada por 210 observações banco/trimestre que efetivamente tiveram divulgação de itens extraordinários de receitas e despesas, ou seja, excluindo as observações que apresentaram saldos zerados.

\subsection{Modelo Operacional da Pesquisa}

Para a realização dos testes empíricos, foi desenvolvido o modelo (3.1) de regressão linear para dados em painel, observando o disposto por Marques (2000), para quem os modelos longitudinais de regressão providenciam maior quantidade de informação, maior variabilidade dos dados, menor multicolinearidade entre as variáveis, maior número de graus de liberdade e maior eficiência quando da estimação de seus parâmetros.

$$
I E_{i t}=\beta_{0}+\beta_{1} L L_{i t}+\beta_{2} \operatorname{Tam}_{i t}+\beta_{3} \operatorname{Cap}_{i t}+\beta_{4} P I B_{t}+\beta_{5} \operatorname{Sel}_{t}+e_{1}
$$

Em que:

$I E_{i t}$ : corresponde aos itens extraordinários informados pelo banco $i$ no trimestre $t$, relativizados pelos ativos totais do início do período;

$L L_{i t}$ : é o lucro líquido contábil - sem considerar os efeitos da classificação de componentes do resultado como itens extraordinários - do banco $i$ no trimestre $t$, ponderado pelos ativos totais do início do período;

$\operatorname{Tam}_{i t}$ : medida de tamanho da entidade, representada pelo logaritmo natural dos ativos totais do banco $i$ no trimestre $t$;

$\operatorname{Cap}_{i t}$ : índice de capitalização, representado pela relação entre o patrimônio líquido e os ativos totais do banco $i$ no trimestre $t$;

$P I B_{t}$ : variação do Produto Interno Bruto no trimestre $t$;

$\mathrm{Sel}_{t}$ : taxa básica de juros da economia, a Selic, no trimestre $t$. 
A variável de interesse do modelo para testar a hipótese de pesquisa é o lucro líquido contábil, sem considerar os efeitos da classificação de itens extraordinários, considerando todos as observações do estudo $(L L)$. A relação entre essa variável e a variável dependente, representada pelos itens extraordinários (IE) permitirá concluir sobre a hipótese de gerenciamento de resultados, com o propósito de alisamento do lucro ajustado ( $L L a j)$, considerando as premissas destacadas na Figura 1.

\begin{tabular}{|l|l|l|}
\hline (=) Lucro Líquido $\boldsymbol{L L}$ & $\begin{array}{l}\text { Reconhecer mais } \boldsymbol{I E} \\
\text { negativos (despesas) na } \boldsymbol{L} \boldsymbol{L} \text { for baixo ou negativo } \\
\text { DRE }\end{array}$ & $\begin{array}{l}\text { IE com sinal negativo no } \\
\text { ajuste do lucro melhora } \\
\text { (aumenta) o lucro ajustado } \\
\text { - proxy do resultado } \\
\text { recorrente }\end{array}$ \\
\hline Se $\boldsymbol{L} \boldsymbol{L}$ for muito alto & $\begin{array}{l}\text { IE com sinal positivo no } \\
\text { ajuste do lucro piora (reduz) } \\
\text { o lucro ajustado - proxy do } \\
\text { resultado recorrente }\end{array}$ \\
\hline (=) Lucro ajustado do período $\boldsymbol{L L a j}$ & \\
\hline
\end{tabular}

Figura 1. Ajuste dos lucros por itens extraordinários, com o propósito de gerenciamento de resultados do lucro ajustado

Assim, haverá evidências de gerenciamento de resultados por alisamento do lucro líquido ajustado pelos itens extraordinários ( $L L a j$ ) se for constatada relação positiva entre a variável dependente (IE) e o lucro líquido contábil $(L L)$ antes dos efeitos da classificação dos itens extraordinários. Essa associação positiva, ou seja, quanto maior (menor) o lucro líquido, maior (menor) a dimensão dos valores classificados como itens extraordinários, resulta no alisamento do lucro líquido ajustado - proxy do lucro recorrente -, conforme previsto na hipótese de pesquisa $H_{1}$. Com isso, a entidade bancária comunica aos investidores, ao regulador e aos depositantes a estabilidade e previsibilidade de sua performance, sinalizando confiança e credibilidade.

Para aprimorar a especificação do modelo, foram incorporadas variáveis explicativas adicionais, para controlar os efeitos de características relativas ao tamanho da entidade (Tam), ao índice de capitalização (Cap) do banco, ao nível de atividade econômica $(P I B)$ e ao patamar da taxa básica de juros da economia ( $\mathrm{Sel}$ ) sobre o nível de divulgação dos itens extraordinários.

A inclusão da variável Tam se justifica pelo fato de as entidades de maior porte necessitarem mais de recursos externos para financiar seus investimentos e, com isso, procurarem apresentar melhor performance, o que pode pressionar o uso de itens extraordinários oportunistas (Barros, Soares, \& Lima, 2013; Cain, Kolev, \& McVay, 2020). Além do mais, considerando que entidades maiores têm maior diversidade de atividades, é natural se esperar que registrem maior participação relativa de itens extraordinários. Quanto ao sinal esperado, considerando que os itens extraordinários podem ser receitas ou despesas, esse pode ser positivo ou negativo. O mais importante, para os fins do presente estudo, é controlar esses efeitos, para não comprometer as conclusões em relação à variável de interesse. 
A incorporação da variável Cap se justifica pelo fato de o nível de capital dos bancos poderem influenciar na divulgação dos itens extraordinários. A princípio, é esperado sinal positivo para a relação entre o nível de capitalização do banco ( $\mathrm{Cap}$ ) e os valores reconhecidos como itens extraordinários (IE), visto que em bancos com maior nível de capital próprio haveria menos incentivos para buscar melhorar o lucro líquido ajustado ( $L L a j)$, fazendo com que a probabilidade de demandas oportunistas da administração seja menor (Dantas \& Medeiros, 2015) - no caso, menor necessidade de informar que maior parcela das despesas teria caráter extraordinário.

No caso do nível de atividade econômica (PIB), Dantas, Medeiros, Galdi e Costa (2013) explicam que em momentos de maior dinamismo econômico, a demanda por operações de crédito aumenta. Assim, supondose que em momentos difíceis essa demanda caia, o PIB pode influenciar o comportamento oportunista do gestor quando ele procurar manter seus níveis de ganhos, o que levaria a uma busca maior por oportunidades de manipulações contábeis, dentre as quais o reconhecimento de mais despesas como itens extraordinários. Assim, seria natural se esperar um sinal positivo para a relação com a variável dependente, $I E$.

No tocante à variável Sel, é esperado que uma mudança na taxa básica de juros da economia, a Selic, afete a expectativa dos agentes no mercado. Como instrumento de política econômica, ela afeta diretamente a liquidez do mercado (Dantas, Medeiros, Galdi \& Costa, 2013), o que pode influenciar, por exemplo, os bancos a reconhecerem (ou não) $I E$ quando faltar (ou houver excesso de) demanda por liquidez, o que justifica a conveniência de se incorporar esse controle, embora não seja possível se especificar o sinal esperado.

A título de análise de sensibilidade, são realizadas quatro estimações do modelo (3.1): com todas as observações banco/trimestre, com e sem tratamento de outliers, por meio da winsorização a 5\%; e apenas com as observações banco/trimestre em que o valor dos itens extraordinários é diferente de zero, também com e sem a winsorização a $5 \%$. O propósito é verificar se os resultados são consistentes em todos os casos. 


\section{Análise dos Resultados}

\subsection{Estatísticas Descritivas}

A primeira etapa dos testes empíricos consistiu na apuração das variáveis do modelo (3.1) para os blocos 1 e 2, cujas estatísticas descritivas são apresentadas na Tabela 1.

Tabela 1

Estatísticas descritivas do modelo (3.1) e composição dos IE nos blocos

\begin{tabular}{|c|c|c|c|c|c|c|}
\hline \multicolumn{7}{|c|}{ Painel A: Estatísticas descritivas das variáveis contínuas do modelo } \\
\hline \multicolumn{7}{|c|}{ Bloco 1} \\
\hline Variáveis & $\mathrm{N}$ & Média & Mediana & Desvio Padrão & Min. & Máx. \\
\hline IE & 417 & $-0,0003$ & 0,0000 & 0,0007 & $-0,0022$ & 0,0075 \\
\hline$L L$ & 417 & 0,0051 & 0,0035 & 0,0085 & $-0,0515$ & 0,0542 \\
\hline Tam & 417 & 24,1571 & 23,8814 & 2,2882 & 18,2983 & 28,3338 \\
\hline Cap & 417 & 0,2090 & 0,1047 & 0,2658 & 0,0461 & 0,9974 \\
\hline$P I B$ & 417 & 0,0016 & 0,0040 & 0,289 & $-0,0916$ & 0,0776 \\
\hline Sel & 417 & 0,0189 & 0,0158 & 0,0094 & 0,0047 & 0,0348 \\
\hline \multicolumn{7}{|c|}{ Bloco 2} \\
\hline Variáveis & $\mathrm{N}$ & Média & Mediana & Desvio Padrão & Mínimo & Máximo \\
\hline IE & 210 & $-0,0052$ & $-0,0004$ & 0,0009 & $-0,0022$ & 0,0075 \\
\hline$L L$ & 210 & 0,0037 & 0,0031 & 0,0028 & 0,0000 & 0,0208 \\
\hline Tam & 210 & 24,1548 & 23,8796 & 1,6420 & 22,1330 & 28,2020 \\
\hline Cap & 210 & 0,1013 & 0,0954 & 0,0343 & 0,0461 & 0,1888 \\
\hline \multicolumn{7}{|c|}{ Painel B: Percentual de IE na composição dos blocos } \\
\hline & & & \multicolumn{2}{|c|}{ Bloco 1} & \multicolumn{2}{|c|}{ Bloco 2} \\
\hline Sem IE & & & \multicolumn{2}{|c|}{$47,00 \%$} & \multicolumn{2}{|c|}{-} \\
\hline \multicolumn{3}{|c|}{ IE negativos (Predomínio de Despesas) } & \multicolumn{2}{|c|}{$49,88 \%$} & \multicolumn{2}{|c|}{$94,12 \%$} \\
\hline \multicolumn{3}{|c|}{ IE positivos (Predomínio de Receitas) } & \multicolumn{2}{|c|}{$3,12 \%$} & \multicolumn{2}{|c|}{$5,88 \%$} \\
\hline
\end{tabular}

Nota: IE: itens extraordinários; LL: lucro líquido contábil, sem os efeitos da reclassificação dos itens extraordinários; Tam : tamanho da entidade; Cap: índice de capitalização; PIB: variação do Produto Interno Bruto; Sel: taxa básica de juros da economia, a Selic.

As estatísticas descritivas das variáveis contínuas no bloco 1 (Painel A) revelam que os valores de itens extraordinários (IE) trimestrais variam entre - $0,22 \%$ e $0,75 \%$ dos ativos, com dispersão equivalente a $0,07 \%$. As medidas de tendência central, média e mediana, próximas de $0 \%$, acabam por revelar para o bloco 1 , que há uma quantidade expressiva de bancos que apresentaram valores zerados na conta de itens extraordinários. Esse fato é também percebido no Painel B, em que se identifica que cerca de $47 \%$ das observações banco/trimestre que compuseram o bloco 1 apresentam itens extraordinários com valor igual a 0. Possíveis justificativas para esses valores zerados é que em determinados trimestres: (i) realmente não ocorreram eventos classificáveis como de natureza extraordinária; (ii) ou eventos de natureza extraordinária ocorreram, mas a administração discricionariamente, reagindo aos incentivos, não faz a evidenciação. Acerca dos itens extraordinários diferentes de zero, ainda no Painel B, bloco 1 , verifica-se que a maior concentração de itens extraordinários reconhecidos foi de prevalência de despesas líquidas, sugerindo que os bancos geralmente reconhecem maiores proporções de despesas, o que resulta no aumento do lucro líquido ajustado ( $L L a j)$ em relação lucro líquido contábil $(L L)$. 
No bloco 2, em que são retiradas as observações banco/trimestre com valor zerado de itens extraordinários para identificar as observações que efetivamente representam itens extraordinários de receitas e despesas, verifica-se no Painel A que as medidas de tendência central, média e mediana, indicam que os itens extraordinários correspondem a cerca de $-0,52 \%$ e - $-0,04 \%$ dos ativos dos bancos, respectivamente, com predomínio do reconhecimento de despesas extraordinárias em relação a receitas, evidenciado pelo sinal negativo. Assim como reportam os dados no bloco 1, essa preponderância de despesas extraordinárias no bloco 2, também pode ser corroborada no Painel B, em que se observa que 94,12\% dos itens extraordinários divulgados pelos bancos são negativos, sugerindo a prática de melhorar o lucro líquido ajustado $(L L a j)$ em relação ao lucro contábil.

No caso do lucro líquido $(L L)$, as estatísticas descritivas (Painel A) demonstram que os dados trimestrais sinalizam um retorno médio sobre os ativos em torno de $0,51 \%$ e $0,37 \%$ ao trimestre, com dispersão de $0,85 \%$ e $0,28 \%$ nos blocos 1 e 2, respectivamente. Situações extremas de retornos positivos (5,42\% e 2,08\% ao trimestre) nos DOIs blocos, ou negativos ( $-5,15 \%$ ao trimestre) para o bloco 1 , e de retorno nulo para o bloco 2, sobre os ativos são pouco recorrentes ou são neutralizadas por observações com sinais em sentido inverso. De qualquer forma, as estatísticas evidenciam, em termos gerais, que essas entidades registram retorno médio em torno de $2,04 \%$ e 1,48\% ao ano (média trimestral anualizada), apontando que o retorno médio do bloco 2, que possui apenas as observações banco/trimestre que apresentaram saldos de itens extraordinários diferentes de zero, é menor do que no conjunto das observações (bloco 1). Essa circunstância pode sinalizar que, por terem menores retornos médios, os bancos com saldos de itens extraordinários diferentes de zero, podem ter mais incentivos para o reconhecimento de itens extraordinários oportunistas, justificando-se, assim, o alisamento do lucro líquido ajustado (LLaj).

Em relação à variável representativa do tamanho (Tam) das instituições, as estatísticas descritivas retratam uma dispersão acentuada em ambos os blocos, evidenciando as diferenças de tamanho entre as entidades - o que é uma característica do mercado bancário brasileiro, com a preponderância de poucos bancos de capital aberto de grande porte, como o Banco do Brasil, Itaú, Bradesco e Santander.

No que diz respeito ao índice de capitalização (Cap), os dados reportam que, em média, os bancos possuem cerca de $21 \%$ de nível de capitalização no bloco 1 e de $10 \%$ no bloco 2 . As estatísticas demonstram que nas extremidades da distribuição existem bancos que possuem uma participação quase integral (99\%) de recursos próprios no financiamento de seus ativos totais, assim como aqueles que possuem participação de 4,6\%, no bloco 1 . Já no bloco 2 , as estatísticas descritivas revelam que nos casos em que há efetiva divulgação de itens extraordinárias (positivos ou negativos) o índice de capitalização é menor, sugerindo que tais entidades têm maior necessidade de gerenciar o lucro líquido ajustado, procurando sinalizar a capacidade de geração de resultados para compensar o menor nível de capital.

Acerca das variações macroeconômicas, os dados sobre o PIB são reveladores da situação econômica verificada no Brasil no período examinado (2016-2020), caracterizada por momentos de declínio econômico e pequeno crescimento, se refletindo em crescimento médio próximo de zero. No caso da variável Sel, por sua vez, os dados capturam o momento de redução da taxa básica de juros entre 2016 e 2020. 


\subsection{Matriz de Correlação e Análise Univariada}

A segunda etapa dos testes compreende a análise da matriz de correlação de Pearson entre as variáveis dependente e independentes do modelo (3.1), cujos resultados são sintetizados na Tabela 2.

Tabela 2

Matriz de correlação de Pearson entre as variáveis do modelo (3.1)

\begin{tabular}{|c|c|c|c|c|c|c|c|c|c|c|c|c|}
\hline \multirow[b]{3}{*}{$I E$} & \multicolumn{6}{|c|}{ Bloco 1} & \multicolumn{6}{|c|}{ Bloco 2} \\
\hline & $I E$ & $L L$ & Tam & Cap & $P I B$ & $\mathrm{Sel}$ & $I E$ & $L L$ & Tam & Cap & $P I B$ & Sel \\
\hline & 1,00 & & & & & & 1,00 & & & & & \\
\hline$L L$ & 0,08 * & 1,00 & & & & & $0,13 * *$ & 1,00 & & & & \\
\hline Tam & $-0,02$ & 0,02 & 1,00 & & & & $-0,07$ & $-0,16 * *$ & 1,00 & & & \\
\hline Cap & $0,13 * * *$ & $0,56 * * *$ & $-0,47 * * *$ & 1,00 & & & $-0,10$ & $0,41 * * *$ & $-0,39 * * *$ & 1,00 & & \\
\hline$P I B$ & 0,02 & 0,03 & 0,00 & $-0,00$ & 1,00 & & 0,06 & $-0,01$ & 0,02 & $-0,01$ & 1,00 & \\
\hline Sel & 0,03 & 0,00 & $-0,05$ & 0,03 & $-0,08$ & 1,00 & 0,04 & 0,03 & $-0,09$ & 0,05 & $-0,11$ & 1,00 \\
\hline
\end{tabular}

Nota: IE: itens extraordinários; LL: lucro líquido contábil, sem os efeitos da reclassificação dos itens extraordinários; Tam: tamanho da entidade; Cap: índice de capitalização; PIB: variação do Produto Interno Bruto; Sel: taxa básica de juros da economia, a Selic. Nível de significância estatística: *** a 1\%; ** a 5\%; e * a 10\%.

Os resultados da análise univariada - correlação entre a variável dependente $I E$ e as variáveis independentes do modelo (3.1) - revelam, inicialmente, correlação positiva com a variável de interesse $L L$, no valor de $8 \%$ e $13 \%$ nos DOIs blocos de dados, revelando os primeiros indícios no sentido previsto na hipótese $H_{1}$, ou seja, quanto maior (menor) o lucro líquido, maior (menor) a proporção dos valores reconhecidos como itens extraordinários, gerando sinais de confirmação da expectativa de alisamento da proxy de resultado recorrente. Para as variáveis independentes de controle - Tam, PIB e Sel-, os coeficientes de correlação com a variável dependente, $I E$, são pouco expressivos, com exceção da variável Cap no bloco 1, que demonstra correlação positiva e significante.

Não obstante esses primeiros indícios a partir da análise univariada, a avaliação mais conclusiva a respeito da relevância das variáveis independentes de interesse e de controle para explicar o nível dos valores reconhecidos como itens extraordinários se dará a partir da análise multivariada, na Seção 4.3.

No que se refere à correlação entre as variáveis independentes, merece destaque a correlação negativa entre as variáveis Sel e PIB, indicando que nesse período contemplado no estudo (2016-2020) há relação negativa entre o patamar da taxa básica de juros da economia e o nível de atividade econômica, sugerindo a influência da taxa de juros no nível de crescimento da economia - quanto menor a taxa de juros, maior o nível de atividade econômica.

As correlações apresentadas na Tabela 2 não são suficientes para alcançar o limite que configuraria alto risco de multicolinearidade, de acordo com a regra prática sugerida por Gujarati (2006), que destaca haver esse risco quando a correlação entre variáveis independentes alcança 0,8 . Adicionalmente, as estatísticas dos testes Variance Inflation Factor (VIF) revelaram que o valor máximo encontrado foi de 2,21 e 1,17, nos blocos 1 e 2, respectivamente, confirmando e reforçando os indícios encontrados na matriz de correlação, afastando o risco de multicolinearidade nas estimações. 


\subsection{Estimação do Modelo}

Para a realização da análise multivariada dos blocos 1 e 2, foram realizados testes para a escolha do método de estimação mais adequado. O resultado do Teste de Chow, que rejeita a hipótese nula, indica que a modelagem de dados em painel é a mais adequada para os DOIs conjuntos de dados. O teste de Breusch-Pagan confirma esse resultado, pois rejeita a hipótese de que o modelo Pools oferece estimadores apropriados, ou seja, existem diferenças estaticamente significativas (ao nível de 5\%) entre as empresas ao longo do tempo que justifiquem a adoção da modelagem de painel. Em seguida, foi realizado o teste de Hausman para verificar qual modelo, entre fixo e aleatório, seria o mais apropriado. Os resultados indicam que a hipótese de que o modelo de correção é adequado, efeitos aleatórios, foi rejeitada, revelando que a estimação mais adequada é através do modelo de efeitos fixos. Assim, a estimação do modelo (3.1) foi realizada por meio de efeitos fixos seccionais, combinando o conjunto completo de dados (bloco 1) e restrita às observações com itens extraordinários diferente de zero (bloco 2), sem tratamento de outliers e com winsorização dos dados a $5 \%$.

Tabela 3

Resultado da estimação do modelo (3.1), por meio de efeitos fixos seccionais

\begin{tabular}{|c|c|c|c|c|}
\hline \multirow{3}{*}{$\begin{array}{l}\text { Modelo: } \\
\text { Variáveis: }\end{array}$} & \multicolumn{4}{|c|}{$I E_{i t}=\beta_{0}+\beta_{1} L L_{i t}+\beta_{2} \operatorname{Tam}_{i t}+\beta_{3} \operatorname{Cap}_{i t}+\beta_{4} P_{I B_{t}}+\beta_{5} \operatorname{Sel}_{t}+e_{1}$} \\
\hline & \multicolumn{2}{|c|}{ Bloco 1} & \multicolumn{2}{|c|}{ Bloco 2} \\
\hline & (1) & (2) & (3) & (4) \\
\hline \multirow{2}{*}{ C } & $-0,0067$ & 0,0076 & $0,0212 * *$ & 0,0183 \\
\hline & $(-1,06)$ & $(-1,01)$ & $(1,19)$ & $(1,10)$ \\
\hline \multirow{2}{*}{$L L$} & $0,0121 *$ & $0,0282 * * *$ & $0,2147^{* * *}$ & $0,2200 * * *$ \\
\hline & $(1,81)$ & $(2,83)$ & $(6,37)$ & $(6,66)$ \\
\hline \multirow{2}{*}{ Tam } & 0,0003 & $-0,0003$ & $-0,0008$ & $-0,0007$ \\
\hline & $(1,06)$ & $(1,00)$ & $(-1,15)$ & $(-1,06)$ \\
\hline \multirow{2}{*}{ Cap } & $-0,0022 * * *$ & $-0,0018^{*}$ & $-0,0268 * * *$ & $-0,0256 * * *$ \\
\hline & $(-2,98)$ & $(-1,88)$ & $(-4,04)$ & $(-4,13)$ \\
\hline \multirow{2}{*}{$P I B$} & 0,0008 & 0,0038 & 0,0028 & 0,0027 \\
\hline & $(0,75)$ & $(0,37)$ & $(1,46)$ & $(1,43)$ \\
\hline \multirow{2}{*}{ Sel } & $0,0069 *$ & 0,0055 & $-0,0034$ & $-0,0022$ \\
\hline & $(1,76)$ & $(1,31)$ & $(-0,29)$ & $(-0,20)$ \\
\hline$N$ & 417 & 417 & 210 & 210 \\
\hline $\mathrm{R}^{2}$ & 0,2513 & 0,028 & 0,2215 & 0,0017 \\
\hline$F$ & 5,26 & 2,16 & 13,70 & 11,65 \\
\hline Prob(F-stat) & 0,0000 & 0,0581 & 0,0000 & 0,000 \\
\hline
\end{tabular}

Notas: IE: itens extraordinários; LL: lucro líquido contábil, sem os efeitos da reclassificação dos itens extraordinários; Tam: tamanho da entidade; Cap: índice de capitalização; PIB: variação do Produto Interno Bruto; Sel: taxa básica de juros da economia, a Selic. Nível de significância estatística: *** a 1\%; ** a 5\%; e * a 10\% (bicaudal). Estimações: (1) conjunto completo de dados, sem tratamento dos outliers; (2) conjunto completo de dados, com winsorização a 5\%; (3) dados restritos aos casos com IE diferente de zero e sem tratamento dos outliers; e (4) dados restritos aos casos com IE diferente de zero e com winsorização a $5 \%$. 
Considerando as quatro estimações, os resultados em relação à variável de interesse revelaram que, independentemente de o conjunto completo de dados ou restrito aos casos em que os itens extraordinários são diferentes de zero ou de tratar ou não os outliers por meio da winsorização, há relação positiva e estatisticamente relevante entre a variável de interesse $L L$ e a variável dependente $I E$. Essas evidências empíricas demonstram que quanto maior (menor) o lucro líquido contábil, antes de se considerar os efeitos dos itens extraordinários, maior (menor) o valor classificado como itens extraordinários, impactando o lucro líquido ajustado - proxy da medida recorrente de resultado. Esses achados corroboram as expectativas da hipótese de pesquisa $H_{1}$, no sentido de que os gestores utilizariam a classificação de itens de resultado (receitas e despesas) como de natureza extraordinária com o propósito de gerenciamento de resultados, suavizando o lucro ajustado, após a exclusão dos efeitos dessa parcela que seria transitória.

A premissa subjacente, portanto, é que os gestores bancários procuram influenciar as expectativas dos usuários em relação aos resultados futuros, utilizando a classificação como "itens extraordinários" para comunicar uma maior estabilidade e previsibilidade da parcela "ordinária" do lucro. Assim, mesmo que a medida de lucro líquido, propriamente dita, sofra variações relevantes, essa medida é "ajustada" mediante a comunicação de que parte desse resultado não teria caráter recorrente. A dimensão e o sinal dessa reclassificação dependem da necessidade e conveniência para transmitir essa suavização. Com isso, transmite aos diversos stakeholders - incluindo investidores, depositantes e o próprio regulador bancário - a percepção de maior segurança e solidez financeira.

Essas evidências empíricas são compatíveis com os achados de McVay (2006), que constatou que os gerentes transferem, de forma oportunista, despesas essenciais para itens extraordinários e posteriormente fazem o caminho inverso, conforme sua conveniência. Também reforçam com o que foi documentado por Fan, Barua, Cready e Thomas (2010), que encontraram evidências de mudança de classificação quando houver restrições para os gestores atenderem a uma série de benchmarks de ganhos por meio da manipulação de accruals.

Dentre as causas de tal comportamento, no mercado brasileiro, cabe mencionar o conflito de interesse de principal versus agente, já que o lucro ajustado é frequentemente uma das medidas de desempenho utilizadas para calcular a remuneração variável dos agentes. No entanto, não há regulação quanto à divulgação do cálculo destas bonificações, já que os padrões que tratam das partes relacionadas apenas orientam quanto à evidenciação do montante pago aos gestores.

É de salientar, assim, que os coeficientes da variável de interesse $(L L)$ das estimações exclusivamente com dados de itens extraordinários diferente de zero (colunas 3 e 4) são maiores do que com o conjunto completo dos dados (colunas 1 e 2) e que as estimações com os dados winsorizados (colunas 2 e 4) são maiores do que sem o tratamento dos outliers (colunas 1 e 3 ). Isso revela que quanto mais restritas as observações se tornam em relação ao reconhecimento dos itens extraordinários, mais pronunciada a relação com a variável dependente, $I E$, e a variável de interesse, $L L$. Isso funciona como um elemento de robustez dos achados, evidenciando não só a consistência e persistência dos resultados, independentemente dos critérios de seleção e tratamento dos dados, mas também do aumento da relevância dos coeficientes de interesse quando adotados critérios mais restritos para tratamento dos dados.

Em relação às variáveis de controle utilizadas, o tamanho das entidades (Tam) não demonstrou associação significativa com a variável dependente nas quatro estimações. No que se concerne ao índice de capitalização (Cap), os resultados das quatro estimações indicam que o nível de capitalização das instituições financeiras analisadas, impactam negativamente no reconhecimento dos itens extraordinários, contrariando as expectativas previstas por Dantas e Medeiros (2015). A relação negativa indica que os bancos que apresentam maiores índices de capital são mais propensos a reconhecer mais preponderantemente IE negativos do que positivos, apesar dessa relação não ser consistente com o fato de que esses bancos, de maiores níveis de capitalização, teriam menos incentivos para melhorar o lucro líquido ajustado (LLaj). 
Em relação às variáveis macroeconômicas representativas do nível de atividade econômica $(P I B)$ e taxa básica de juros da economia $(\mathrm{Sel})$ os resultados demonstram que, de forma geral, essas variáveis não explicam a divulgação pela entidade de parte dos resultados como itens extraordinários. Isso revela que o comportamento dos valores classificados como de natureza transitória não é influenciado por condições macroeconômicas.

O conjunto dos resultados em relação às variáveis de controle ajuda a evidenciar a relevância do nível do lucro líquido contábil como determinante da divulgação dos itens extraordinários, tendo em vista a pouca ou nenhuma representatividade das variáveis de controle.

\section{Considerações Finais}

Este estudo teve por propósito investigar evidências da prática de gerenciamento de resultados por parte dos bancos brasileiros, por meio da classificação de determinados itens de resultados como de natureza "extraordinária", buscando influenciar as expectativas dos usuários das demonstrações quanto à persistência do lucro nos períodos futuros.

Os resultados demonstram associação positiva entre o lucro líquido contábil e os itens extraordinários, o que sugere que os gestores utilizam a classificação como itens extraordinários para suavizar a proxy de lucro recorrente, sinalizando a estabilidade dos resultados futuros. Outro importante achado deste estudo refere-se ao fato de que os bancos evidenciam mais despesas em detrimento de receitas como itens extraordinários.

Além de melhorar a percepção do mercado, a evidenciação de um melhor desempenho financeiro corrobora o conflito de interesse descrito na Teoria da Agência, pois o lucro ajustado é frequentemente utilizado como medida de desempenho para a remuneração variável dos gestores (agentes). No entanto, as entidades não costumam divulgar as medidas de desempenho utilizadas para bonificação por não haver regulação quanto à evidenciação do cálculo da remuneração.

A pesquisa contribui para o desenvolvimento da literatura sobre o uso de medidas non-gaap no mercado de capitais, em que as entidades divulgadoras procuram influenciar as expectativas dos investidores, com uso de medidas não disciplinadas nas normas contábeis, com foco no impacto da divulgação de itens extraordinários pelos bancos brasileiros. Contribui também com as discussões do ED/2019/7 do Iasb, uma vez que traz à tona a importância de uma diretriz para os itens extraordinários, de forma a amenizar a assimetria informacional. Os achados também ampliam o conhecimento sobre as formas e os determinantes de gerenciamento de resultados na indústria bancária, além de destacar as possibilidades de análise e utilização das informações relativas a itens extraordinários.

A título de limitações, destacam-se: o tamanho da população, devido à restrição do número de bancos brasileiros de capital aberto e com dados disponíveis na base de dados consultada; a Refinitiv Eikon pode promover algum ajuste na classificação dos itens extraordinários, que pode representar algum grau de diferença em relação ao que é divulgado pelos bancos nas medidas non-gaap adicionais às demonstrações financeiras; e a própria restrição dos achados ao mercado bancário brasileiro, embora possa servir como indícios do que pode ocorrer em outros segmentos econômicos.

A título de sugestões para aprofundamento de estudos a respeito do tema, sugere-se avaliar os efeitos da divulgação de efeitos recorrentes e não recorrentes em empresas não financeiras e verificar até que ponto essa divulgação influenciará a prática do gerenciamento de resultados documentado neste estudo. 


\section{Referências}

Alali, F., \& Jaggi, B. (2010). Earnings versus capital ratios management: role of bank types and SFAS 114. Review of Quantitative Finance and Accounting, 36(1), 105-132. Doi: https://DOI.org/10.1007/ s11156-010-0173-4

Andrade, G. V., \& Murcia, F. D. R. (2019). A critical analysis on the additional adjustments considered in the disclosure of the non-GAAP "adjusted EBITDA" measure in the reports of Brazilian listed companies. Revista de Educação e Pesquisa em Contabilidade (REPeC), 13(4), 477-494. Doi: https:// DOI.org/10.17524/repec.v13i4.2412

Araújo, A. M. H. B., Lustosa, P. R. B., \& Paulo, E. (2018). The cyclicality of loan loss provisions under three diferent accounting models: the United Kingdom, Spain, and Brazil. Revista Contabilidade e Finanças, 29(76), 97-113. Doi: http://dx.DOI.org/10.1590/1808-057x201804490

Barros, C. M. E., Soares, R. O., \& Lima, G. A. S. F. (2013) A relação entre governança corporativa e gerenciamento de resultados em empresas brasileiras. Revista de Contabilidade e Organizações, 7(19), 27-39. Doi: 10.11606/rco.v7i19.55509

Barua, A., Lin, S., \& Sbaraglia, A. (2010). Earnings Management Using Discontinued Operations. The Accounting Review, 85, 1485-1509. Doi: https://DOI.org/10.2139/ssrn.1245863

Beatty, A., \& Harris, D. G. (1999). The effects of taxes, agency costs and information asymmetry on earnings management: A comparison of public and private firms. The Review of Accounting Studies, 4(3\&4), 299-326. Doi: https://DOI.org/10.1023/A:1009642403312

Beatty, A., Ke, B., \& Petroni, K. R. (2002). Earnings management to avoid earnings declines across publicly and privately held banks. The Accounting Review. 77(3), 547-570. Doi: 10.2308/accr.2002.77.3.547

Cain, C. A., Kolev, K. S., \& McVay, S. (2020). Detecting opportunistic special items. Management Science, 66(5), 2099-2119. Doi: 10.2139/ssrn.1267022

Cohen, D. A., \& Zarowin, P. (2007). Earnings Management over the Business Cycle. Working Paper, New York University, New York, 1-39. Recuperado de https://citeseerx.ist.psu.edu/viewdoc/download? DOI=10.1.1.1060.381\&rep=rep1\&type $=$ pdf

Curcio, D., \& Hasan, I. (2015). Earnings and capital management and signaling: the use of loanloss provisions by European banks. European Journal of Finance, 21(1), 26-50. Doi: 10.1080/1351847X.2012.762408

Dantas, J. A., Galdi, F. C., Capelleto, L. R., \& Medeiros, O. R. (2013). Discricionariedade na Mensuração de Derivativos como Mecanismo de Gerenciamento de Resultados em Bancos. Revista Brasileira Finanças, 11(1), 17-48. Doi: 10.12660/rbfin.v11n1.2013.3658

Dantas, J. A., \& Medeiros, O. R. (2015). Determinantes da qualidade da auditoria independente em bancos. Revista Contabilidade \& Finanças, 26(67), 43-56. Doi: 10.1590/1808-057x201400030

Dantas, J. A., Medeiros, O. R., Galdi, F. C., \& Costa, F.M. (2013). Securities-Based Earnings Management in Banks: Validation of a Two-Stage Model. Revista Contabilidade \& Finanças, 24(61), 37-54. Doi: 10.1590/S1519-70772013000100005

Dantas, J. A., Medeiros, O. R., \& Lustosa, P. R. B. (2013). O Papel de variáveis econômicas e atributos da carteira na estimação das provisões discricionárias para perdas em operações de crédito nos bancos brasileiros. Brazilian Business Review, 10(4), 69-95. Doi: 10.15728/bbr.2013.10.4.3 
Dechow, P. M., \& Skinner, D. (2000). Earnings Management: reconciling the views of accounting academics, practitioners and regulators. Accounting Horizons, 14(2), 235-250. Doi: https://DOI. org/10.2308/acch.2000.14.2.235

Dechow, P. M., Sloan, R. G., \& Sweeny, A. P. (1995). Detecting earnings management. The Accounting Review, 70(2), 193-225. Recuperado de http://www.jstor.org/stable/248303

Dittmann, I., \& Maug, E. (2007). Lower Salaries and No Options? On the Optimal Structure of Executive Pay. The Journal of Finance, 62(1), 303-343. Recuperado de http://www.jstor.org/stable/4123463

Eisenhardt, K. M. (1988). Agency and Institutional Theory Explanations: The Case of Retail Sales Compensation. The Academy of Management Journal, 31(3), 488-511. Doi: https://DOI. org/10.2307/256457

Fan, Y., Barua, A., Cready, W. M., \& Thomas, W. B. (2010). Managing earnings using classification shifting: Evidence from quarterly special items. Accounting Review, 85(4), 1303-1323. Doi: 10.2308/ accr.2010.85.4.1303

Flores, E., \& Lopes, A. B. (2019). Decréscimo na Relevância da Informação Contábil das Distribuidoras de Energia Elétrica no Brasil no Período Pós-IFRS. Revista Brasileira de Gestão de Negócios, 21(4), 928-952. Doi: 10.7819/rbgn.v21i5.4023

Gabriel, F., \& Corrar, L. J. (2010). Gerenciamento de resultados e de capital no sistema bancário brasileiro uma investigação empírica nas aplicações em títulos e valores mobiliários. Revista de Contabilidade do Mestrado em Ciências Contábeis da UERJ, 15(2), 49-62. Doi: tps://DOI.org/10.12979/rcmccuerj. v15i2.5499

Gujarati, D. N. (2006). Econometria básica. 4 ed. São Paulo.

Healy, P., \& Whalen J.M. (1999). A Review of the Earnings Management Literature and its Implications for Standard Setting. Accounting Horizons, 13(1), 365-384. Doi: 10.2139/ssrn.156445

IAS 1, December 2014. IAS 1 - Presentation of Financial Statements. Recuperado de https://www.ifrs.org/ issued-standards/list-of-standards/ias-1-presentation-of-financial-statements/.

IASB, December 2019. Exposure Draft ED/2019/7 - General Presentation and Disclosures - Illustrative Examples. Recuperado de https://www.ifrs.org/projects/work-plan/primary-financial-statements/.

IFRS 14, January 2014. IFRS 14 - Regulatory Deferral Accounts. Recuperado de https://www.ifrs.org/ issued-standards/list-of-standards/ifrs-14-regulatory-deferral-accounts/.

Jensen, M., \& Meckling, W. (1976) Theory of the firm: Managerial behavior, agency costs, and ownership structure. Journal of Financial Economics, 3, 305-360. Doi: https://DOI.org/10.1016/0304405X(76)90026-X

Jones, J. J. (1991). Earnings management during import relief investigations. Journal of Accounting Research, 29(2), 193-228. Doi: https://DOI.org/10.2307/2491047

Kanagaretnam, K., Krishnan, G., \& Lobo, G. J. (2010). An empirical analysis of auditor independence in the banking industry. The Accounting Review, 85(6), 2011-2046. Doi: 10.2308/accr.2010.85.6.2011

Kanagaretnam, K., Lim, C. Y., \& Lobo, G. J. (2010). Auditor Reputation and Earnings Management: International Evidence from the Banking Industry. Journal of Banking and Finance, 34(10), 23182327. Doi: $10.1016 /$ j.jbankfin.2010.02.020 
Koch, T. W., Waggoner, D. F., \& Wall, L. D. (2018). Incentive compensation, accounting discretion and bank capital. Journal of Economics and Business, 95(1), 119-140. Doi: 10.1016/j.jeconbus.2017.03.001

Li, N., Su, H., Dong, W., \& Zhu, K. (2018). The effect of non-recurring items on analysts' earnings forecasts. China Journal of Accounting Research, 11(1), 21-31. Doi: 10.1016/j.cjar.2017.10.001

Lopes, L. M. S., Pinheiro, F. M. G., \& Dias Filho, J. M. (2014). Gerenciamento de Resultados: um estudo das empresas do setor de telecomunicações no Brasil. Revista de Contabilidade do Mestrado em Ciências Contábeis da UERJ, 19(1), 80-94. Recuperado de http://www.atena.org.br/revista/ojs-2.2.306/index.php/UERJ/article/view/1864/1802

Macedo, M. A. S, \& Kelly, V. L. A. (2016). Gerenciamento de Resultados em Instituições Financeiras no Brasil: Uma Análise com Base em Provisões para Crédito de Liquidação Duvidosa. Revista Evidenciação Contábil \& Finanças, 4(2), 82-96. Doi: 10.18405/recfin20160206

Marques, L. D. (2000) Modelos dinâmicos com dados em painel: revisão da literatura. Série Working Papers do Centro de Estudos Macroeconômicos e Previsão (CEMPRE) da Faculdade de Economia do Porto, Portugal, n. 100. Recuperado de http://wps.fep.up.pt/wps/wp100.pdf

Martinez, A. L. (2001). Gerenciamento dos resultados contábeis: estudo empírico das companhias abertas brasileiras (Tese de doutorado). Faculdade de Economia, Administração e Contabilidade, Universidade de São Paulo, São Paulo, SP, Brasil. Recuperado de https://www.teses.usp.br/teses/ disponiveis/12/12136/tde-14052002-110538/pt-br.php

Martinez, A. L. (2013). Gerenciamento de resultados no Brasil: um survey da literatura. BBR: Brazilian Business Review, 10(4), 1-31. Doi: 10.15728/bbr.2013.10.4.1

McVay, S. E. (2006). Earnings Management Using Classification Shifting: An Examination of Core Earnings and Special Items. The Accounting Review, 81(3), 501-531. Recuperado de http://www. jstor.org/stable/4093104

Pelucio-Grecco, M. C., Geron, C. M. S., Grecco, G. B., \& Lima, J. P. C. (2014). The effect of IFRS on earnings management in Brazilian non-financial public companies. Emerging Markets Review, 21, 42-66. Doi: https://DOI.org/10.1016/j.ememar.2014.07.001

Resolução $\mathrm{BCB} \mathrm{n}^{\circ}$ 2, de 12 de agosto de 2020. Consolida os critérios gerais para elaboração e divulgação de demonstrações financeiras individuais e consolidadas pelas administradoras de consórcio e pelas instituições de pagamento e os procedimentos para elaboração, divulgação e remessa de demonstrações financeiras que devem ser observados pelas instituições financeiras e demais instituições autorizadas a funcionar pelo Banco Central do Brasil. Recuperado de https://www. in.gov.br/en/web/dou/-/resolucao-bcb-n-2-de-12-de-agosto-de-2020-271965214

Schipper, K. (1989). Commentary on earnings management. Accounting Horizons, 3(4), 91-102. Recuperado de https://www.proquest.com/openview/177246e104b43553542ab048997f1a4e/1? pq-origsite $=$ gscholar $\&$ cbl $=3330$

Shrieves, R. E., \& Dahl, D. (2003). Discretionary accounting and the behavior of japanese banks under financial duress. Journal of Banking and Finance, 27(7), 1219-1243. Doi: 10.1016/S0378$4266(02) 00252-2$ 
Silva, C. A. M., Niyama, J. K., Rodrigues, J. M., \& Lourenço, I. M. E. C. (2018). Gerenciamento de resultados por meio da perda estimada de créditos em bancos brasileiros e luso-espanhóis. Revista Contemporânea de Contabilidade, 15(37), 139-157. Doi: 10.5007/2175 -8069

Silva, K. O., \& Robles Junior, A. (2018). Provisão para créditos de liquidação duvidosa (PCLD) calculada conforme as normas do BACEN e IFRS: comparação. Contabilidade, Atuária, Ciências e Informação (Cafi), 1(1), 4-21. Doi: 10.23925/cafi.v1i1.36949

Soedarmono, W., Pramono, S. E., \& Tarazi, A. (2017). The procyclicality of loan loss provisions in Islamic banks. Research in International Business and Finance, 39(B), 911-919. Doi: 10.1016/j. ribaf.2016.05.003

Suzart, J. A. S. (2015). Decompondo o Lucro Contábil: Uma Análise Dos Bancos Marka e Fonte Cindam em Período Anterior à Mudança Cambial de 1999. Revista de Gestão e Contabilidade da UFPI, 2(1), 40-60. Doi: 10.26694/2358.1735.2015.v2ed11979

Warfield, T. D., Wild, J. J., \& Wild, K. L. (1995). Managerial ownership, accounting choices, and informativeness of earnings. Journal of Accounting and Economics, 20(1), 61-91. Doi: 10.1016/01654101(94)00393-J.

Watts, R., \& Zimmerman, J. (1986). Positive Accounting Theory. Prentice-Hall, Englewood Cliffs, NJ.

Zhuang, Z. (2016). Discussion of 'An evaluation of asset impairments by Australian firms and whether they were impacted by AASB 136'. Accounting and Finance, 56(1), 289-294. Doi: 10.1111/acfi.12199 